resulting photographs are measured on special micrometer machines, the positions of the spectral lines being determined with reference to a comparison spectrum of the iron arc or some other convenient standard source.

Particular reference may be made to the work on extra-galactic nebulæ, the spectra of which almost without exception show displacements corresponding to large velocities of recession. The objects in question are generally extremely faint, and in addition their light is spread over an appreciable area of the sky, instead of being concentrated like that of a star. They are more difficult to observe than the diffuse and planetary nebulæ, since they have absorption, not emission, spectra. Pioneer work was done by V. M. Slipher at the Lowell Observatory, Flagstaff, but the more extensive recent measurements have been made at Mt. Wilson, where spectra of extremely small dispersion are taken with a special short focus camera lens working at $f 0 \cdot 6$. The slit is used very wide and the exposures are sometimes very long, extending over several nights. In the photographs it is generally possible to distinguish only one or two of the strongest features of the spectrum, but the displacements, thanks to their great size, are usually determined well within ten per cent.

Reverting to more normal stellar work, the errors of measurement of radial velocities, as one might expect, vary a great deal according to the dispersion of the spectra and the nature of the spectrum lines. With a one prism instrument giving 25 or $30 \mathrm{~A} . / \mathrm{mm}$. at $\mathrm{H}_{\gamma}$, the probable error per plate is approximately $1 \mathrm{~km}$. $/ \mathrm{sec}$. in the case of a star with many sharp spectral lines, but with some spectra where the lines are few and nebulous, this error may easily exceed $5 \mathrm{~km}$./sec. Systematic errors have in the past usually been evaluated by intercomparison of results from different observatories. Their average value is generally rather less than $1 \mathrm{~km}$./sec. Now, however, as work is being pushed further to fainter apparent magnitudes, there is considerably less overlap than formerly between the work at one observatory and another, and standard stars are coming into use for the purpose of checking systematic errors. Alist of such stars was published some years ago by the radial velocity commission of the International Astronomical Union and has proved very valuable. It is at present being revised and extended to fainter stars.

An inispection of Dr. Moore's catalogue gives some idea of the total progress made to date in this work. Thanks chiefly to the Lick Observatory, all stars have been adequately observed down to magnitude 5.51, but apart from this no group of stars has been completely observed over both northern and southern hemispheres. In the northern sky various groups of objects such as the Boss stars, the brighter dwarfs, the O to B5 stars down to magnitude $7 \cdot 5$, and certain classes of variables, have been observed, and further systematic work is being pushed forward, particularly at the Lick, Victoria and Mt. Wilson observatories. On the other hand, the southern sky below declination $-25^{\circ}$, with the exception of the brighter stars just mentioned, remains practically untouched. Neglecting for the moment the fact that there are known to be many variable and peculiar stars of great interest in this region, knowledge of which would be very greatly advanced by radial velocity observations, this gap in our data is most serious in work on stellar motions. Until it is filled, observational studies of such questions as galactic rotation and certain other features of stellar movements must necessarily be incomplete.

Unfortunately, there seems to be no immediate certainty of a suitable telescope being established in the southern hemisphere for this purpose. At the recent meetings at Cambridge, Massachusetts, the radial velocity commission and later the general assembly of the International Astronomical Union, fully alive to the unsatisfactory nature of the present situation, passed a resolution asking that every effort be made to further any project aiming at the establishment and efficient working in the southern hemisphere of a large reflecting telescope for stellar spectroscopy and in particular for the determination of radial velocities. It seems unfortunate that some of the large sums of money devoted to several schemes at present on foot to build large instruments in the northern hemisphere, could not have been diverted towards filling this need in the southern sky.

Apart from this gap, which will have to be filled at some time, future work in radial velocities is likely to concentrate on refined observations of the brightest stars, on variables and peculiar objects, and on obtaining large numbers of velocities of fainter stars for statistical work. These last need not be of very great accuracy, although systematic errors will have to be carefully watched. There is in these three directions an almost unlimited field for large telescopes.

\title{
Obituary
}

\section{Mr. Frank Finn}

$\mathrm{F}$ RANK FINN, whose recent death, at sixtyfour years of age, we regret to record, was an exhibitioner of Brasenose College, Oxford, and an excellent classical scholar. Whilst at Oxford he took a great interest in ornithology, both as an observer of birds and a systematic naturalist. $\mathrm{He}$ acquired a reputation amongst dealers and spent a great deal of his time in identifying collections of skins. This pursuit, unfortunately, occupied much of the time that he should have devoted to classics, with the result that his academic success by no means equalled his capacity. It may be said that this showed almost the leading defect in his character, which prevented him from being really successful in any of his undertakings. $\mathrm{He}$

No. 3292, VoL. 130] 
was always more interested in something which it was unnecessary to do at the time than in the immediate duty before him.

After taking his degree with honours in 'Greats', Mr. Finn went on an expedition to tropical Africa and spent a considerable time travelling, observing, and collecting. On his return he became assistant to Col. A. W. Alcock, who was then in charge of the Indian Museum. There also it was characteristic of him that he devoted more time to observing animals in the Zoological Gardens in Calcutta and its vicinity than to his official duties.

In 1903, Mr. Finn resigned his post and returned to England. The rest of his life was occupied by various minor appointments, none of which he cared to hold very long; by writing for the Press, and by writing books on natural history, the chief of which are: "Indian Sporting Birds", 1915 ; "How to Know the Indian Waders", 1906; "The World's Birds", 1908 ;. "Game Birds of India and Asia", 1911 ; "Bird Behaviour", 1919 ; and with E. Kay Robinson, "Birds of Our Country". 2 Vols. 1922-23.

Mr. Finn had a most remarkable memory for facts, and there is no doubt that in his powers of observation and his real knowledge of birds and mammals, he had the making of a very great naturalist. For many years, however, he suffered from serious ill-health which made him irregular in his methods of working. He had, however, many delightful qualities and every naturalist who came intimately in contact with him had the highest possible appreciation of his knowledge and abilities.

WE regret to announce the following deaths :

Dr. Ernest Clarke, C.V.O., distinguished for his work in ophthalmic surgery, a manager and vicepresident of the Royal Institution, on November 22, aged seventy-five years.

Mr. W. H. Patchell, consulting engineer, president of the Institution of Mechanical Engineers in 1924-25, on November 24, aged seventy years.

Mr. Charles M. Stuart, first headmaster (18881922) of St. Dunstan's College, Catford, who did much for the promotion of scientific method in education, on November 22, aged seventy-five years.

\section{News and Views}

Honour for Prof. Karl Pearson, F.R.S.

Prof. KarL Pearson, of University College, London, has been awarded the Rudolf Virchow medal by the Berlin Gesellschaft für Anthropologie, Ethnologie und Urgeschichte. The award is made in recognition of Prof. Pearson's conspicuous services for the advancement of the study of human biology, and especially his pioneer work in the field of biometrics and his contributions to the study of eugenics, in which he has carried on and extended the work of the late Francis Galton. In conveying the announcement of the award, Prof. Eugen Fischer, president of the society, recalls the fact that up to the present the only recipients of the medal have been von der Steinen and Koch-Grünberg, the ethnologists ; Olshausen and Heger, the archæologists ; Toldt and Hans Virchow, anatomists; and lastly Erwin Baur, the geneticist. The value of the award is enhanced not only by its significance as a recognition of the international character of science, but also by the fact that on this, the first occasion on which the award has been made to a scientific worker outside the boundaries of Central European countries, the choice has fallen on one who is British. This, however, is not the only tribute which has been paid recently to the position in international scientific circles held by Prof. Pearson. The Sixth International Congress of Genetics, when assembled last summer in plenary session at Ithaca, New York, in conveying cordial greetings to Prof. Pearson and "best wishes for his health and long success and satisfaction in his scientific work", acknowledged the great indebtedness of the science of genetics to the statistical methods developed by him and now universally used.

No. 3292, Vol. 130]
To no one could these honours have fallen more appropriately. As Galton professor of eugenics in the University of London and as director of the Francis Galton Laboratory of National Eugenics, Prof. Pearson has attained a world-wide reputation for the originality and fertility of his application of statistical methods to the problems of biology and anthropology. His statistical methods have been developed in innumerable papers contributed to scientific periodicals and in a number of books, of which the "Grammar of Science" (1899) and "National Life from the Standpoint of Science" (1901) have exerted no inconsiderable influence on the development of scientific thought. These methods have been applied to the study of topics to which their adaptability would at one time have been inconceivable to any but the fertile genius of Francis Galton, whose life and letters were edited with discrimination and judgment by Prof. Pearson in three volumes $(1914,1924$ and 1930). Yet notwithstanding the range and quality of his output, the great achievement of his fifty years teaching and work in London has been his success in inspiring and directing the work of others, for the most part his own pupils, who with him have contributed to the great advance in the exact scientific study of man and his heredity during the last generation. Prof. Pearson's success in this direction has been conspicuous in his editorship of Biometrika, a periodical for the statistical study of biological problems, which was founded by himself, the late W. F. R. Weldon and Sir Francis Galton. Happily, when Prof. Pearson retires from active teaching, as he proposes to do at the end of the current session, he will retain the editorship of this periodical. 